\title{
Responsibilities of Weed Technology Reviewers
}

The editor's objective in selecting reviewers is to obtain assistance from scientists who may have more expertise on the manuscript topic than the associate editor or editor. Therefore, the reviewer's primary responsibilities are to evaluate the scientific quality and accuracy of data interpretation and to provide comments that help the author to improve the manuscript. The author, associate editor, and editor will appreciate and use comments concerning style and format, but this is secondary to the reviewer's scientific evaluation. Below are responsibilities of reviewers in approximate order of importance.

1. Review the manuscript promptly. A manuscript should be reviewed within 2 weeks of receipt, although 4 weeks is the maximum acceptable delay. Usually a reviewer can meet a self-imposed deadline of 2 weeks as readily as a 4-week deadline. Remember that you appreciate a prompt turn-around time when your manuscript is reviewed, and the obligation is reciprocal.

2. Review the scientific quality of the manuscript.

a. Are the purpose and objectives clearly stated?

b. Were the methods appropriate and adequately described?

c. Were statistics used and interpreted properly? Spot check calculations for errors, e.g., column and row totals, unusual yields indicating incorrect conversion factors, Duncan's multiple range test letter sequences.

d. Are conclusions consistent with the data presented?

3. Review the writing quality.

a. Are the appropriate literature citations included? b. Are statements clear, understandable, accurate, and consistent with the data presented?

c. Do some sections need condensed, or omitted? Are data in the tables and figures repeated too much in the text?

d. Are the tables and figures clear, readable, and easy to understand?

e. Are the title and abstract clear, concise, and representative of the manuscript?

f. Are appropriate "Additional index words" listed?

4. Review for consistency with WEED TECHNOLOGY guidelines.

a. Is the overall format correct, i.e., meaningful section and subsection divisions, chemical and binomial names included, literature cited in the text, correct footnote ...?

b. Are entries in Literature Cited correct? Only an experienced weed scientist is likely to catch errors like spelling of Mikkel versus Mickel or inversions like 1987 versus 1978 or typographical errors like 1986 versus 1976.

c. Are the grammar and syntax correct?

Note: Most manuscripts will be revised after your review, and the technical editor will check grammar, punctuation, abbreviations, spelling (including chemistry and binomial names), syntax, and format. Therefore, a reviewer is not expected to edit word by word, especially when extensive rewriting will be required. However, missing or incorrect information or consistent errors should be identified, so that authors can prepare a relatively "clean" revised manuscript.

STATEMENT OF OWNERSHIP, MANAGEMENT AND CIRCULATION (Required by 39 U.S.C. 3685) Date of Filing-September 6, 1995. Title of PublicationWEED TECHNOLOGY; Publication No. 001-191; Frequency of Issue-quarterly; No. of Issues Published Annually-4; Annual Subscription Price-\$60.00; Complete Mailing Address of Know Office of Publication-Weed Science Society of America, 1508 W. University Ave., Champaign, 61821-3133,; Complete Mailing Address of the Headquarters of General Business of the Publisher-Weed Science Society of America, 1508 W. University Ave., Champaign, 61821-3133,; Publisher-Weed Science Society of America, 1508 W. University Ave., Champaign, 61821-3133,; Editor-C. L. Foy, 503 Price Hall, Virginia Tech, Blacksburg, VA 24061; Owner-Weed Science Society of America, 1508 W. University Ave., Champaign, 61821-3133,; Known Bondholders, Mortgagees, and Other Security Holders Owning or Holding 1 Percent or More of Total Amount of Bonds, Mortgages or Other Securities-none; A.Total no. copies printed (net press run), average 3,616, actual 3,6107; B.Paid and/or Requested Circulation 1.Sales through dealers and carriers, street vendors and counter sales, average none, actual none; $2 . M a i l$ Subscriptions, average 2,951, actual 2,997; C.Total Paid and/or Requested Circulation, average 2,951, actual 2,997; D.Free Distribution by Mail, Carrier or Other Means, average none, actual none; E. Total Distribution(sum of $\mathrm{C}$ and D), average 2,951, actual 2,997; F.Copies not distributed 1.Office use, left over, unaccounted, spoiled after printing, average 5665, actual 3610; 2.Return from News Agents, average none, actual none; G.Total(sum of E and F-should equal net press run shown in A), average 3,616, actual 3,6107. I certify that the above statement made by me are correct and complete. Robert A. Schmidt. 